\title{
Outcomes Research
}

National Cancer Institute

\section{Source}

National Cancer Institute. Outcomes Research. NCI Thesaurus. Code C15365.

The study of the end results of health services, with the intention of providing scientific evidence relating to the value of the decisions made by all who participate in the health care process. 